avoidance of repetition and the excision of some of the more speculative matter. We believe that, by doing so, Dr. Sluder would secure a fuller appreciation of the great value of much of the work that he has put into this volume.

\title{
CORRESPONDENCE
}

\section{ADRENALINE IN GLAUCOMA AND IRITIS}

\section{To the Editor of The British Journal of Ophthalmology}

DEAR SIR,-German and American literature has had 'many. references to the injection of adrenaline for glaucoma. Thus Hamburger (Berlin), 1924, advised a subconjunctival injection of $0.2-0.4 \mathrm{c.cm}$. suprarenin (Hochst) after the instillation of 2 per cent. holocaine in the case of failure to lower tension with the usual miotics. Further F. H. Rodkin (San Francisco) recommended subconjunctival injections of atropine and epinephrine in acute irido-cyclitis in cases where instillation of atropine or the use of crystals of atropine fail to dilate the pupil. In asthma the subcutaneous dosage of adrenaline usually employed is 5 to 10 minims, while in cases of shock we used to inject intravenously with saline 10 to 20 minims. Again in cases of heart failure $10 \mathrm{minims}$ have been injected into the heart. Therefore, when I commenced to use adrenaline subconjunctivally, I did not realize the importance of limiting the dose to Hamburger's recommendation of $0.2-0.4 \mathrm{c.cm}$.

I have employed adrenaline in three patients, one of whom died within five minutes after injection, in one signs of general vasoconstriction were evident, whilst the pulse became so weak that strophanthin was employed. The third showed signs of vasoconstriction.

Case 1.-A patient, 49 years of age. An Elliot trephine operation was performed on both eyes for glaucoma. A haemorrhage occurred in one eye and as it was slow in absorbing, I decided to try the effect of adrenaline. On about the fourth day after operation, I injected subconjunctivally about 0.5 c.c. of adrenaline 1 in 1,000 . Immediately the patient complained of a violent pain in the back of her head, became dyspnoeic, blanched, and died within five minutes from the time of injection.

Case 2.-A patient, 44 years of age. A frail woman who had tuberculous iritis, but no signs of general T.B.

The slit-lamp showed large deposits on the posterior surface of the cornea, many synechiae, and pupil filled with a membrane. The patient had been treated with tr. of iodine by mouth, tuberculin (B.E.), subconjunctival injections of hydrarg. cyanide $1 / 5,000$, with 
acoine and aspiration of the aqueous with injection of air. To none of these treatments had the patient objected. Owing to the difficulty in treating the synechiae I injected two minims of atropine, 2 per cent. and four minims of adrenaline, 1 in 1,000. Almost immediately, i.e., as I stood by her bed, the patient complained of a pricking sensation in her hands and arms, followed by numbness, a sensation of numbness in the back of her head and palpitations. Her teeth chattered, and a shivering sensation passed over her whole body. The pulse became rapid, feeble and irregular, digitalin gr. 1/50 and morphia gr. 1/4, and later strophanthin, gr. 1/200 were administered. These various sensations lasted about twenty minutes.

Case 3.-A patient, 41 years of age. A robust woman had acute keratitis and irido-cyclitis of the left eye. Being unable to find a focus of infection, I treated the patient with atropine, dionine, adrenaline, milk injections, and subconjunctival injections of hydrarg. cyanide $1 / 5,000$ with acoine 1 per cent. Before the onset of irido-cyclitis, whilst the keratitis alone was being treated, the patient received subconjunctival injections of phenolaine. To none of these injections did the patient object, and so I resort $\epsilon \mathrm{d}$ to a subconjunctival injection of two minims atropine, 2 per cent. and four minims adrenaline, 1 in $1 / 1,000$. The patient's pulse did not become weak, nevertheless, she complained of her legs becoming cold, a lump on her chest, a numbness on the top of her head, and a choking sensation. Thus in cases 2 and 3 , I carefully measured the adrenaline, whilst in case 1 , I can only say the injection was about 0.5 c.c., i.e., I may have injected more. The injections in cases 2 and 3 did not dilate the pupils. I am so alarmed at the result of these injections that I shall not inject adrenaline subconjunctivally again. But in cases of glaucoma I shall soak cotton wool in adrenaline and place it under the upper lid after applications of holocaine 2 per cent., for I found this efficacious in one case in which the tension fell from 70 to 40 (McLean's tonometer) in a patient on whom I previously had done an iridodialysis, which had resulted at once in tubular vision, which passed on to complete blindness in some months. This mode of applying adrenaline is not only efficacious but was carried on at home daily by the patient's wife. An alternative is to use a tuberculin syringe graduated in fractions of a c.c. and adhere closely to Hamburger's dosage of $0.2-$ 0.4 c.c.

\section{Yours truly,}

OPHTHALMIC SURGEON.

\section{REFERENCES}

Hamburger.-Abstracted in Ars. Medica, No. 6, p. 270, 1924 ; No. 7, p. 276, 1925 ; No. 1, p. 35, 1926. Brit. Jl. of Ophthal., Vol. XI, pp. 239, 614, 1927.

Rodkin, F. H. - Treatment of Irido-cyclitis by Subconjunctival Injections of Atropine and Epinephrine. Amer. Jl. of Ophthal., p, 24, January, 1926. 